\title{
What Is Known and Unknown About Twice-Weekly Hemodialysis
}

\author{
Yoshitsugu Obi ${ }^{a, b}$ Rieko Eriguchia, ${ }^{a}$ Shuo-Ming Ou ${ }^{a-e}$ Connie M. Rhee ${ }^{a, b}$ \\ Kamyar Kalantar-Zadeh ${ }^{a, b, f}$ \\ ${ }^{a}$ Division of Nephrology and Hypertension, University of California Irvine, Orange, CA, USA; ${ }^{b}$ Harold Simmons \\ Center for Kidney Disease Research and Epidemiology, Orange, CA, USA; 'Division of Nephrology, Department of \\ Medicine, Taipei Veterans General Hospital, Taipei, Taiwan; ${ }^{d}$ School of Medicine, National Yang-Ming University, \\ Taipei, Taiwan; ${ }^{\mathrm{e}}$ Institute of Clinical Medicine, National Yang-Ming University, Taipei, Taiwan; ${ }^{\mathrm{f}}$ Department of \\ Medicine, VA Long Beach Health Care System, Long Beach, CA, USA
}

\section{Key Words}

Twice-weekly hemodialysis · Incremental dialysis . Individualized therapy - Residual kidney function . End-stage renal disease $\cdot$ Health-related quality of life

\begin{abstract}
Background: The 2006 Kidney Disease Outcomes Quality Initiative guidelines suggest twice-weekly or incremental hemodialysis for patients with substantial residual kidney function (RKF). However, in most affluent nations de novo and abrupt transition to thrice-weekly hemodialysis is routinely prescribed for all dialysis-naïve patients regardless of their RKF. We review historical developments in hemodialysis therapy initiation and revisit twice-weekly hemodialysis as an individualized, incremental treatment especially upon first transitioning to hemodialysis therapy. Summary: In the 1960 's, hemodialysis treatment was first offered as a life-sustaining treatment in the form of long sessions ( $\geq 10$ hours) administered every 5 to 7 days. Twice- and then thrice-weekly treatment regimens were subsequently developed to prevent uremic symptoms on a long-term basis. The thriceweekly regimen has since become the 'standard of care' despite a lack of comparative studies. Some clinical studies have shown benefits of high hemodialysis dose by more fre-
\end{abstract}

quent or longer treatment times mainly among patients with limited or no RKF. Conversely, in selected patients with higher levels of RKF and particularly higher urine volume, incremental or twice-weekly hemodialysis may preserve RKF and vascular access longer without compromising clinical outcomes. Proposed criteria for twice-weekly hemodialysis include urine output $>500 \mathrm{ml} /$ day, limited interdialytic weight gain, smaller body size relative to RKF, and favorable nutritional status, quality of life, and comorbidity profile. Key Messages: Incremental hemodialysis including twice-weekly regimens may be safe and cost-effective treatment regimens that provide better quality of life for incident dialysis patients who have substantial RKF. These proposed criteria may guide incremental hemodialysis frequency and warrant future randomized controlled trials. $\quad 02015 \mathrm{~S}$. Karger AG, Basel

\section{Introduction}

Almost a decade has passed since the 2006 Kidney Disease Outcomes Quality Initiative (KDOQI) guidelines recommended twice-weekly hemodialysis (HD) treatment regimens for patients with substantial residual kidney function (RKF) [1]. However, with regards to $\mathrm{HD}$

\section{KARGER 125}

(c) 2015 S. Karger AG, Base

0253-5068/15/0404-0298\$39.50/0

E-Mail karger@karger.com

www.karger.com/bpu
Kamyar Kalantar-Zadeh, MD, MPH, PhD

Harold Simmons Center for Kidney Disease Research and Epidemiology

University of California Irvine, 101 The City Drive South, City Tower

Suite 400 - ZOT: 4088, Orange, CA 92868 (USA)

E-Mail kkz@uci.edu 
Table 1. Proposed criteria for twice-weekly HD

1. Urine output $>0.5$ liters/day

2. Interdialytic weight gain $<2.5 \mathrm{~kg}$ (or $<5 \%$ of dry weight) at intervals of $3-4$ days

3. Limited or readily manageable cardiovascular or pulmonary symptoms without clinically significant fluid overload

4. Appropriate body size relative to RKF

5. Infrequent or readily manageable hyperkalemia $(\mathrm{K}>5.5 \mathrm{mEq} / \mathrm{l})$

6. Infrequent or readily manageable hyperphosphatemia $(\mathrm{P}>5.5 \mathrm{mg} / \mathrm{dl})$

7. Good nutritional status without overt hypercatabolic state

8. Appropriate responsiveness to anemia therapy with $\mathrm{Hb}>8 \mathrm{~g} / \mathrm{dl}$

9. Limited or easily manageable comorbid conditions

10. Satisfactory health-related quality of life

Patients should meet the first criterion (urine output $>0.5$ liters/day) plus $\geq 5$ of the other 9 criteria, followed by monthly reevaluation. Consider transition to thrice-weekly HD regimen if patient's urine output decreases $(<0.5$ liters/day) or patient's nutritional status or general health condition shows a deteriorating trend over time. These criteria are general rather than specific and should be refined for use in clinical studies and clinical decision making. Adapted from Kalantar-Zadeh [3]. Hb = Hemoglobin; $\mathrm{K}=$ potassium; $\mathrm{P}=$ phosphorus.

adequacy targets, it is only the 'golden rule' for 1.2 singlepool Kt/V for thrice-weekly regimens that has been remembered in most dialysis-therapy practicing circles. To that end, thrice-weekly HD has continued to be regarded as the standard of care of HD treatment for patients with end-stage renal disease (ESRD) [2]. Whereas thriceweekly HD appears to be an appropriate treatment for many ESRD patients, they continue to show markedly decreased health-related quality of life (HRQoL) and survival [3]. The cost of HD treatment is inherently high, typically 100-300 USD per treatment in most industrialized nations; hence it places an enormous financial burden on the healthcare system worldwide. Given the cumulative evidence discussed below, we believe that it is time to revisit the so-called taboo of twice-weekly HD, as an important form of individualized and incremental treatment for selected patients with ESRD $[4,5]$, especially upon their de novo transition to dialysis. Table 1 shows criteria recently developed by international consensus for evaluating the appropriateness of twice-weekly HD (see Kalantar-Zadeh et al. [3] for more details).

\section{Historical Changes in HD Frequency}

Historically and upon conception and establishment of HD therapy, duration and frequency of HD treatment was determined to prevent uremic symptoms, such as lethargy, pruritus, nausea, vomiting, volume overload, and peripheral neuropathy. In the early 1960 's, ESRD patients were prescribed one long HD session (20-24 hours in duration) every 5 to 7 days [6]. Given the inadequate treatment of uremia with such sporadic HD treatments and the exceptional severity of kidney failure among those patients who had little to no remaining residual kidney function (RKF), the frequency of HD treatments was gradually increased over time, concurrent with improvement in HD techniques and systems. By the late 1960's, the twice-weekly schedule was employed in many programs (fig. 1), but a high prevalence of uremic neuropathy was still observed [7]. During congressional discussions surrounding the Medicare ESRD Program legislature in 1973, the thrice-weekly schedule was thought to provide a more beneficial HD regimen and was considered 'the best compromise' to deliver HD treatment to as many patients as possible with the limited resources available [6]. Prior to this, HD was literally a life-sustaining intervention in only selected ESRD patients, and very few diabetic or elderly patients were accepted for treatment.

Since then, there has been rapid and innovative progress in HD techniques, equipment, and practices, including fully computerized HD machines, better biocompatibility and performance of dialysis membranes, higher purity of dialysate, and more frequent creation and greater longevity of arteriovenous fistulas. These advances have made HD treatments more streamlined, efficient, and less costly, allowing for an expansion of patients who are eligible for HD treatment, including those who are elderly and/or have multiple comorbidities requiring earlier transition to dialysis while still having substantial RKF. Indeed, in 2012, more than $40 \%$ of ESRD patients who started HD were diabetic, and more than $50 \%$ were aged $\geq 65$ years in both the US and Japan $[8,9]$. Treatment time to achieve targeted solute clearance was also decreased over time [10]. International data has shown that over the period of 1999 to 2011, 
Treatment regimen

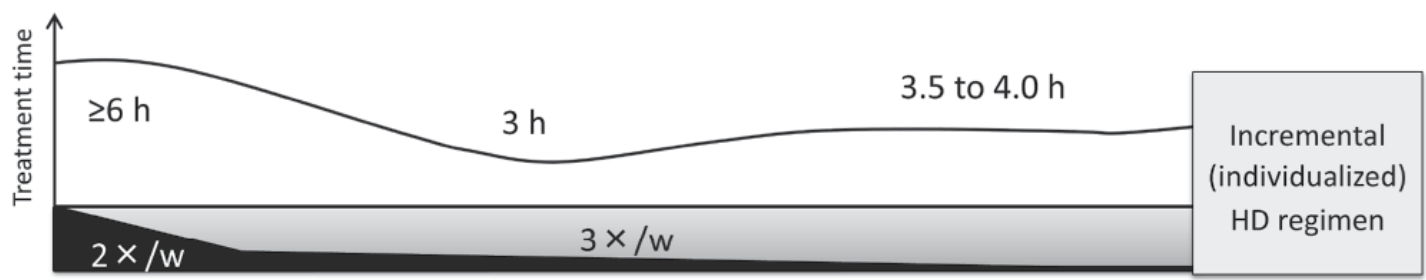

Adequacy index

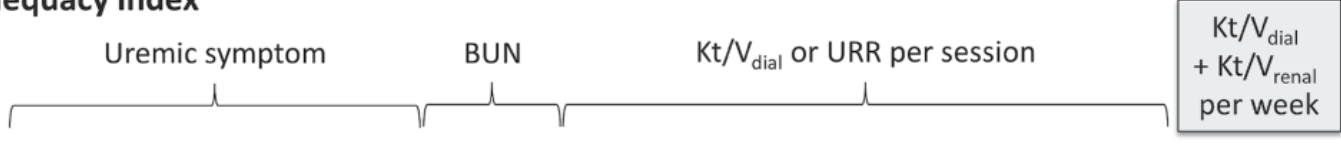

Major historical events

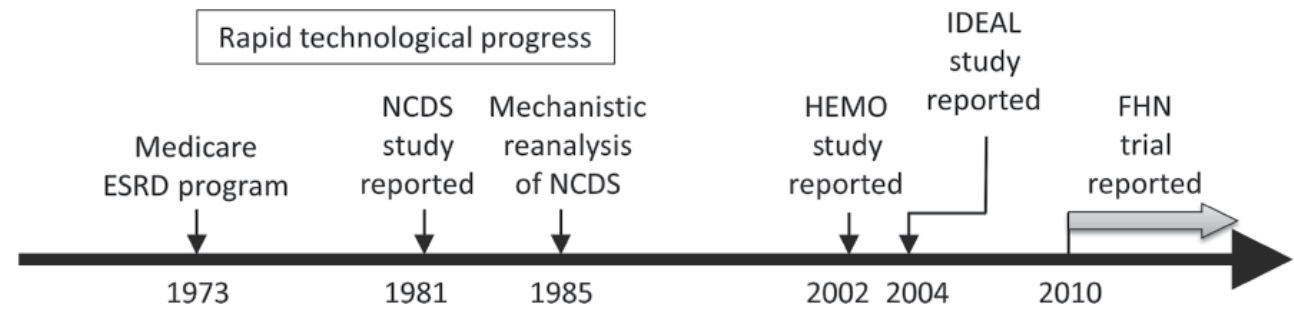

Fig. 1. History of treatment regimens and the major events that affected clinical practice in maintenance hemodialysis. Figure adapted from Lacson and Brunelli [10]. BUN = Blood urea nitrogen; URR = urea reduction ratio.

mean treatment time was approximately 220 and 240 minutes in the US and Japan, respectively [11]. These changes along with the thrice-weekly HD schedule enabled dialysis facilities to provide two alternating everyother-day schedules (Monday-Wednesday-Friday or Tuesday-Thursday-Saturday) across $\geq 3$ shifts per day, leaving Sunday as the universal 'day-off for both patients and dialysis staff [3]. Nevertheless, in some countries such as the UK, there are dialysis centers that also offer Sunday schedules [12].

\section{Conflicting Results from Clinical Trials Evaluating HD Adequacy: Effect Modification by Residual Kidney Function}

As HD treatment became established and widely available, the goals of caring for ESRD patients shifted from a focus upon increasing short-term survival towards improving long-term outcomes. There was strong belief that greater solute clearance should lead to better survival. This notion was further strengthened by the $1981 \mathrm{Na}-$ tional Cooperative Dialysis Study (NCDS) which showed that maintaining lower time-averaged blood urea nitrogen concentrations decreases treatment withdrawals and hospitalizations [13]. Although the HEMO Study failed to prove this concept by using higher HD dose or highflux membranes [14], the Frequent Hemodialysis Network (FHN) Daily Trial reported somewhat favorable effects of 6-times-per-week in-center HD largely upon changes in left ventricular mass and physical health composite score, as compared with conventional thrice-weekly HD [15]. The FHN Nocturnal Trial showed similar trends [16], but the extended follow-up study found higher mortality in patients randomly assigned to frequent nocturnal HD [17].

Although these results may seem conflicting, the beneficial effects of high HD dose or frequency in some of these studies are likely observed in patients with little or no RKF. The NCDS trial limited participants to those who had creatinine clearances $<3 \mathrm{ml} / \mathrm{min}$ [13], but in contemporary practice, patients are typically transitioned to HD when kidney function is above this threshold. A subgroup analysis of the HEMO study suggested that pa- 
Fig. 2. Benefits from a less or more frequent HD schedule and their potential effect modifiers.

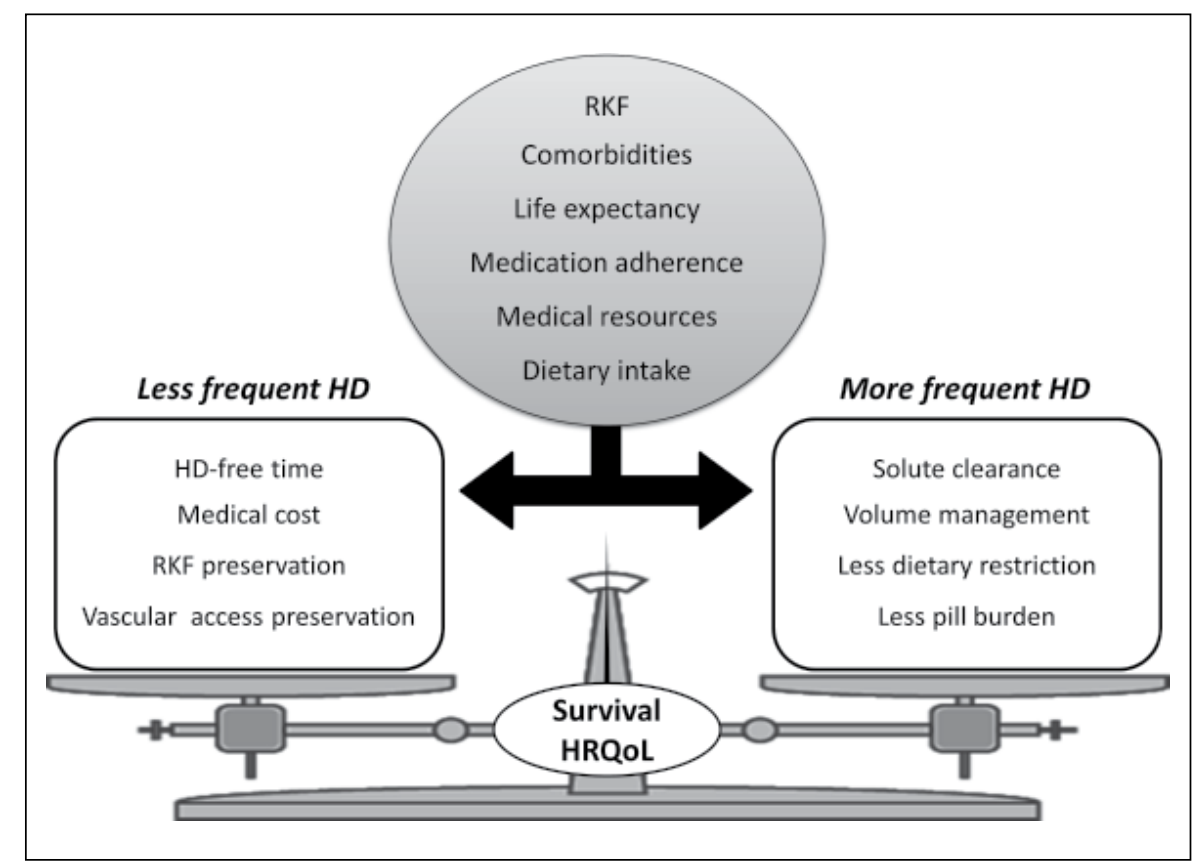

tients with longer dialysis vintage ( $\geq 3.7$ years), most of whom were presumed to have little RKF, may benefit from receipt of the high-flux dialysis membrane [14]. In the FHN Daily Trial, $84 \%$ of patients had dialysis vintages $\geq 2$ years, and $66 \%$ were anuric [15]. In contrast, in the FHN Nocturnal Trial where higher mortality was observed in the frequent nocturnal HD group, patients had a comparatively lower median dialysis vintage of approximately 1 year, and $47 \%$ of patients had urine volume $>500 \mathrm{ml} /$ day [17]. It is important to note that in the latter study, patients who received more frequent HD had significantly faster loss of their RKF [18]. This unfavorable outcome has been highlighted in commentaries by Daugirdas et al. [18], Kalantar-Zadeh et al. [3, 4], Rhee et al. [2], and Wong et al. [5]. The Initiating Dialysis Early and Late (IDEAL) study also showed similar results, such that earlier initiation of HD did not improve survival nor major clinical outcomes [19], suggesting that HD treatment offers little benefit to patients with substantial RKF.

Therefore, the expected benefit of HD treatment should be weighed against potential adverse effects on a case-by-case basis as discussed below (fig. 2). The balance between the benefits and harms of HD treatment may be influenced by several factors such as life expectancy, dietary intake (i.e., protein, sodium, potassium, and phosphorus), medication adherence, access to medical resources, and, most importantly, RKF.

Twice-Weekly Hemodialysis

\section{Potential Benefits of Twice-Weekly HD}

We argue that twice-weekly HD in the current era is not a suboptimal treatment regimen for patients with substantial RKF as compared with conventional thriceweekly HD. Using the equation for standard Kt/ $\mathrm{V}_{\text {urea }}$ by Daugirdas et al. [20], urea clearances in thrice-weekly HD versus twice-weekly HD treatment regimens with 1.2 single-pool Kt/V and 210-minute treatment times are equivalent to $9.3 \mathrm{ml} / \mathrm{min}$ versus $6.15 \mathrm{~m} / \mathrm{min}$, respectively. This differential in urea clearance is similar to the minimum threshold RKF level of $3.0 \mathrm{ml} / \mathrm{min}$ at which twice-weekly HD is recommended by the KDOQI guidelines [1]. This major differential in clearance bears substantial clinical significance, and it is doubtful that other interventions (such as increasing HD dose per session, enhancing dietary management, and use of drugs including erythropoiesis-stimulating agents, phosphate binders, and calcimimetics) offer the same degree of benefit as preservation of RKF. Given that over 100,000 patients initiate HD annually in the US, among whom $45 \%$ have estimated glomerular filtration rates $\geq 10 \mathrm{ml} / \mathrm{min} / 1.73 \mathrm{~m}^{2}$ upon dialysis initiation [8], appropriate implementation of twice-weekly HD may have a favorable impact upon ESRD patient outcomes as well as considerable economic advantages. Currently available evidence for less frequent $\mathrm{HD}$ is summarized in table 2 . 
Table 2. Summary of studies examining the association between infrequent hemodialysis and clinical outcomes

\begin{tabular}{llll}
\hline Study & Cohort & Results \\
Author (Journal, Year) & $\begin{array}{l}\text { Exposure } \\
\text { (vs. thrice-weekly } \\
\text { HD) }\end{array}$ & \\
\hline
\end{tabular}

\section{Mortality}

Hanson et al. [27]

(Am J Nephrol 1999)

Incident HD Twice-weekly HD
$(\mathrm{n}=4,888)$
Prevalent HD
$(\mathrm{n}=10,179)$

Incident HD Twice-weekly HD

$(\mathrm{n}=639)$

Prevalent HD

$(\mathrm{n}=673)$

\begin{tabular}{lll}
\hline $\begin{array}{l}\text { Stankuviene et al. [39] } \\
\text { (Medicina 2010) }\end{array}$ & $\begin{array}{l}\text { Incident HD } \\
(\mathrm{n}=2,428)\end{array}$ & $\begin{array}{l}\text { Once- and } \\
\text { twice-weekly HD }\end{array}$ \\
\hline $\begin{array}{l}\text { Elamin and Abu-Aisha [40] } \\
\text { (Arab J Nephrol Transplant 2012) }\end{array}$ & $\begin{array}{l}\text { Prevalent HD } \\
(\mathrm{n}=2,012)\end{array}$ & Twice-weekly HD \\
\hline $\begin{array}{l}\text { Fernández-Lucas et al. [23] } \\
\text { (Nephrologia 2012) }\end{array}$ & $\begin{array}{l}\text { Incident HD } \\
(\mathrm{n}=95)\end{array}$ & Incremental HD \\
\hline
\end{tabular}

\section{Residual renal function}

Lin et al. [22]

(Nephrology 2009)

Fernández-Lucas et al. [23]

(Nephrologia 2012)

\begin{tabular}{lll}
\hline $\begin{array}{l}\text { Caria et al. [38] } \\
(\text { BMC Nephrology 2014) }\end{array}$ & $\begin{array}{l}\text { Incident HD } \\
(\mathrm{n}=68)\end{array}$ & $\begin{array}{l}\text { Once-weekly HD } \\
\text { with low protein diet }\end{array}$ \\
\hline $\begin{array}{l}\text { Zhang et al. [24] } \\
\text { (Am J Nephrol 2014) }\end{array}$ & $\begin{array}{l}\text { Incident HD } \\
(\mathrm{n}=85)\end{array}$ & Twice-weekly HD
\end{tabular}

\section{Nutritional parameters}

Supasyndh et al. [41]

(J Med Assoc Thai 2009)

Lin et al. [22]

(Nephrology 2009)

\begin{tabular}{lll}
$\begin{array}{l}\text { Nutritional parameters } \\
\begin{array}{l}\text { Supasyndh et al. [41] } \\
\text { (J Med Assoc Thai 2009) }\end{array}\end{array}$ & $\begin{array}{l}\text { Prevalent HD } \\
(\mathrm{n}=142)\end{array}$ & Twice-weekly HD \\
\hline $\begin{array}{l}\text { Lin et al. [22] } \\
\text { (Nephrology 2009) }\end{array}$ & $\begin{array}{l}\text { Prevalent HD } \\
(\mathrm{n}=74)\end{array}$ & Twice-weekly HD \\
\hline
\end{tabular}

Updated from Rhee et al. [2]. $(\mathrm{n}=74)$
Prevalent HD Twice-weekly HD Greater RKF preservation (without adjustment)

\begin{tabular}{lll}
$\begin{array}{l}\text { Incident HD } \\
(\mathrm{n}=95)\end{array}$ & Twice-weekly HD & Greater RKF preservation (without adjustment) \\
\hline $\begin{array}{l}\text { Incident HD } \\
(\mathrm{n}=68)\end{array}$ & $\begin{array}{l}\text { Once-weekly HD } \\
\text { with low protein diet }\end{array}$ & Greater RKF preservation (without adjustment) \\
\hline $\begin{array}{l}\text { Incident HD } \\
(\mathrm{n}=85)\end{array}$ & Twice-weekly HD & $\begin{array}{l}\text { Greater RKF preservation (without adjustment) } \\
\text { Odds ratio for faster RKF loss was 7.2 after } \\
\text { adjustment for sex, urea reduction rate, and } \\
\text { intradialytic hypotension episode. }\end{array}$ \\
\hline
\end{tabular}

Lower adjusted mortality risk in both incident and prevalent HD patients. This association was attenuated after adjustment for RKF at HD initiation (available only in incident patients).

Similar adjusted mortality risk overall as well as subgroups of incident and prevalent patients (RKF data not available).

Higher adjusted mortality (RKF data not available)

Higher 1-year crude mortality (85\% vs. $89 \%$ )

Greater crude survival

intradialytic hypotension episode.

Similar nutritional laboratory parameters and protein intake, but greater energy intake

Similar nutritional laboratory parameters

\section{Preservation of $R K F$}

RKF in dialysis patients plays important roles in fluid and salt removal, effective phosphorus excretion, middlemolecule clearance, and endogenous vitamin $\mathrm{D}$ and erythropoietin production [2-4]. It has also been associated with higher HRQoL, lower inflammation, reduced left ventricular hypertrophy, and better survival. However, RKF decline is faster in patients receiving thriceweekly HD therapy than in those receiving peritoneal dialysis [21]; whereas HD per se may accelerate RKF decline by episodic ischemic insults to the kidney, provision of less frequent $\mathrm{HD}$ may mitigate this potential risk of HD. Indeed, consistent with the results from the FHN study that showed faster loss of RKF in frequent nocturnal HD compared with conventional thrice-weekly HD [18], several non-controlled clinical studies indicated that twiceweekly HD may preserve RKF [22-24]. In a study of 85 incident HD patients in Shanghai initiated on either a twice-weekly or thrice-weekly HD regimen, a greater proportion of patients receiving twice-weekly HD had 
preservation of RKF during the first year of HD initiation [24]. There are complementary studies suggesting that dialysis dose did not have a significant impact on outcomes in patients with certain levels of RKF [25, 26], supporting the notion that twice-weekly HD for such patients may be an appropriate choice.

\section{Survival and HD Frequency}

In a retrospective study cohort conducted by the US Renal Data System in the late 1990 s, $6.1 \%$ and $2.7 \%$ of the patients underwent twice-weekly HD treatment regimens in 4,888 incident and 10,179 prevalent HD patients, respectively [27]. Factors associated with twice-weekly HD schedules included older age, female gender, white race, shorter dialysis vintage, higher serum albumin, lower serum creatinine, lower body mass index, and greater baseline RKF at the time of HD initiation. After adjustment for demographics, cause of ESRD, comorbid conditions, and nutritional status, twice-weekly HD regimens showed $21 \%$ and $24 \%$ lower mortality risk in incident and prevalent HD patients, respectively, versus thrice-weekly HD. This survival differential was attenuated upon adjustment for baseline RKF, which was available only in incident HD patients. There are two additional studies that also reported better survival among patients who received twice-weekly HD without adjustment for RKF $[23,28]$. None of these studies have examined the level of RKF where patients could benefit from twiceweekly HD.

\section{Other Potential Benefits}

Having twice-weekly HD sessions will also result in less frequent arteriovenous fistula or graft cannulations, which may prolong the longevity of dialysis vascular access [4]. The FHN study has shown that compared with conventional $\mathrm{HD}$, more frequent $\mathrm{HD}$ was associated with higher risk of vascular complications including repair, loss, or vascular access related hospitalization; this was thought to more likely be a consequence of increased HD frequency than heightened surveillance [29]. Additionally, by having one less HD treatment a week, patients can spend more time engaging in activities outside of the dialysis unit, which may lead to substantially better quality of life [2-4]. Ironically, certain populations such as patients who are elderly, have advanced cancer, or have other severe comorbid conditions are less likely to benefit from more frequent dialysis, and less frequent $\mathrm{HD}$ with conservative management may be considered as a palliative option even when such patients have limited RKF.

Twice-Weekly Hemodialysis

\section{Potential Disadvantages of Twice-Weekly HD}

\section{Interdialytic Weight Gain and Ultrafiltration}

Several studies have identified the long (2-day) interdialytic interval as an independent risk factor for all-cause mortality and cardiovascular hospitalization in patients treated with thrice-weekly HD [30-32], likely due to fluid overload and/or electrolyte derangements. Although the potential complications of the long interval may seem to counteract the benefits of twice-weekly HD, adverse outcomes associated with the long interdialytic interval were not observed among incident HD patients [30], many of whom likely have a higher RKF than prevalent patients and thus maintained better electrolyte and fluid balance. Moreover, it is possible that the higher mortality of the long interdialytic interval relates to excess dialysis and abrupt removal and shifts of fluid and electrolyte (e.g., potassium) [12].

There may be misconceptions that larger interdialytic weight gains (IDWG) will be observed with twice-weekly HD schedules compared with thrice-weekly schedules, and that aggressive ultrafiltration may be required to remove excess fluid accumulated during the interdialytic HD interval. Whereas large IDWGs may promote left ventricular hypertrophy and congestive heart failure by increasing afterload and myocardial oxygen demand [33], this should not be the case in patients with substantial RKF who are compliant with restriction of fluid intake. Indeed, it is plausible that more frequent HD may lead to greater IDWGs and cardiac structural abnormalities over time due to faster loss of RKF [18]. Rapid ultrafiltration rates may also contribute to intradialytic hypotension, subclinical cardiac stunning, and myocardial ischemia [34]. Greater IDWG ( $\geq 5 \%$ of dry weight) and higher ultrafiltration rates $(\geq 10 \mathrm{ml} / \mathrm{h} / \mathrm{kg})$ are associated with higher risk of mortality $[35,36]$, and patients with advanced heart disease may require longer or more frequent HD treatments [37]. Aggressive ultrafiltration often causes cramping, dizziness, and fatigue that makes dialysis intolerable. Other potential unfavorable features of twice-weekly HD that bear mention include persistent azotemia and electrolyte disturbances (e.g., hyperkalemia, hypercalcemia, and hyperphosphatemia), but these complications are less likely to occur in patients with substantial RKF who are the optimal candidates for twice-weekly HD [3].

\section{Nutritional Status and Dietary Intake}

Whereas thrice-weekly HD patients are recommended to have high dietary protein intake $(1.2-1.3 \mathrm{~g} / \mathrm{kg} /$ day), which is in sharp contradistinction to non-dialysis 
CKD patients who are prescribed low protein diets (0.6$0.7 \mathrm{~g} / \mathrm{kg} /$ day), there is no known dietary recommendation for patients on twice-weekly therapy with substantial RKF. Dietary intake may also appear to affect the fine balance of HD frequency in conflicting ways, as patients with intact appetite usually have good nutritional status, while their serum concentrations of urea nitrogen, potassium, and phosphorus tend to be high.

Caria et al. [38] from Italy has recently suggested that infrequent HD regimens of once-weekly HD, complemented by very low protein, low phosphorus diets supplemented with ketoacids had favorable impact on preserving patients' urine output. We currently propose an averaged dietary protein intake of $0.8-1.0 \mathrm{~g} / \mathrm{kg} /$ day to most twice-weekly HD with substantial RKF, while on non-dialysis versus dialysis days the dietary protein intake may be comparatively lower versus higher, respectively.

\section{Other Considerations}

Incremental transition from twice-weekly to thriceweekly HD may be eventually considered when increase in dialysis dose fails to compensate for decreased RKF. However, RKF decline rates differ across HD patients, and without regular assessment of patients' RKF and urine output, the appropriate juncture for increasing HD frequency may be overlooked or missed. As this time, there is little evidence as to which patients prescribed twice-weekly HD may continue to benefit from this treatment regimen over time, as opposed to require transition to more frequent HD regimens. It may also be challenging to convince patients who are accustomed to the twice-weekly HD regimen to increase their dialysis time and/or frequency, which may be inevitable if their RKF declines over time. We feel that the criteria set forth by international consensus (see table 1) is an excellent tool to routinely assess the need for such transitions and to communicate with patients when the appropriate time arrives.

\section{Conclusions}

Incident dialysis patients with substantial RKF (e.g., $\mathrm{KRU}>3.0 \mathrm{ml} / \mathrm{min} / 1.73 \mathrm{~m}^{2}$ [1]) are likely good candidates for twice-weekly HD, while those with little or no RKF may benefit from conventional thrice-weekly or even more frequent $\mathrm{HD}$, depending on other factors including age, comorbid conditions, and dietary intake. Twice-weekly HD schedules may play an important role as the first regimen for patients incrementally initiating $\mathrm{HD}$, and also as a palliative approach for conservative management in certain populations in order to optimize HRQoL and resource utilization. However, implementation twice-weekly HD has been hindered by a paucity of evidence of its associated outcomes (benefits and risks). To that end the traditional view of nephrology communities in affluent nations has been that twice-weekly HD is an inferior option and a discussion taboo; however there has very recently been a surge of provocative literature leading to its reconsideration [2-5]. The recently developed consensus criteria for implementing twice-weekly $\mathrm{HD}$ is an important development in promoting the concept of individualized incremental HD regimens, and they need to be validated and refined in future research studies.

\section{Financial Support and Sponsorship}

KKZ is supported by the National Institutes of Health-National Institute of Diabetes, Digestive and Kidney Disease (NIHNIDDK) grant K24-DK091419 as well as philanthropist grants from Mr. Harold Simmons, Mr. Louis Chang, Dr. Joseph Lee, and AVEO. YO is supported by the Shinya Foundation for International Exchange of Osaka University Graduate School of Medicine Grant. CMR is supported by the NIH-NIDDK grant K23DK102903.

\section{Conflicts of Interest}

KKZ has received honoraria and/or support from Abbott, Abbvie, Alexion, Amgen, American Society of Nephrology, AstraZeneca, Aveo, Chugai, DaVita, Fresenius, Genetech, Haymarket Media, Hospira, Kabi, Keryx, NIH, National Kidney Foundation, Relypsa, Resverlogix, Sanofi, Shire, Vifor, and ZS-Pharma.

References

$\checkmark 1$ Hemodialysis Adequacy 2006 Work Group Clinical practice guidelines for hemodialysis adequacy, update 2006. Am J Kidney Dis 2006;48(suppl1):S2-S90.

2 Rhee CM, Unruh M, Chen J, Kovesdy CP, Zager P, Kalantar-Zadeh K: Infrequent dialysis: a new paradigm for hemodialysis initiation. Semin Dial 2013;26:720-727.

-3 Kalantar-Zadeh K, Unruh M, Zager PG, Kovesdy CP, Bargman JM, Chen J, Sankarasubbaiyan S, Shah G, Golper T, Sherman RA, Goldfarb DS: Twice-weekly and incremental hemodialysis treatment for initiation of kidney replacement therapy. Am J Kidney Dis 2014;64:181-186.

4 Kalantar-Zadeh K, Casino FG: Let us give twice-weekly hemodialysis a chance: revisiting the taboo. Nephrol Dial Transplant 2014; 29:1618-1620. 
5 Wong J, Vilar E, Davenport A, Farrington K: Incremental haemodialysis. Nephrol Dial Transplant 2015;30:1639-1648.

-6 Scribner BH, Cole JJ, Ahmad S, Blagg CR: Why thrice weekly dialysis? Hemodial Int 2004;8:188-192.

7 De Palma JR, Bolton CF, Baltzan MA, Baltzan RB: Adequate hemodialysis schedule. $\mathrm{N}$ Engl J Med 1971;285:353-354.

8 US Renal Data System, USRDS 2012 Annual Data Report: Atlas of Chronic Kidney Disease and End-Stage Renal Disease in the United States, National Institutes of Health, National Institute of Diabetes and Digestive and Kidney Diseases, Bethesda, MD, 2012. http://www.usrds.org/atlas12.aspx (accessed September 28, 2014).

-9 Nakai S, Hanafusa N, Masakane I, Taniguchi M, Hamano T, Shoji T, Hasegawa T, Itami N, Yamagata K, Shinoda T, Kazama JJ, Watanabe Y, Shigematsu T, Marubayashi S, Morita O, Wada A, Hashimoto S, Suzuki K, Nakamoto H, Kimata N, Wakai K, Fujii N, Ogata S, Tsuchida K, Nishi H, Iseki K, Tsubakihara Y: An overview of regular dialysis treatment in Japan (as of 31 December 2012). Ther Apher Dial 2014;18:535-602.

10 Lacson E Jr., Brunelli SM: Hemodialysis treatment time: a fresh perspective. Clin J Am Soc Nephrol 2011;6:2522-2530.

11 Annual Report of the Dialysis Outcomes and Practice Patterns Study: Hemodialysis Data 1997-2011. Arbor Research Collaborative for Health, Ann Arbor, MI, 2012.

12 Rhee CM, Kalantar-Zadeh K: Implications of the long inter-dialytic gap: a problem of excess accumulation vs. excess removal? Kidney Int 2015;88:442-444.

13 Lowrie EG, Laird NM, Parker TF, Sargent JA: Effect of the hemodialysis prescription of patient morbidity: report from the National Cooperative Dialysis Study. N Engl J Med 1981; 305:1176-1181.

14 Eknoyan G, Beck GJ, Cheung AK, Daugirdas JT, Greene T, Kusek JW, Allon M, Bailey J, Delmez JA, Depner TA, Dwyer JT, Levey AS, Levin NW, Milford E, Ornt DB, Rocco MV, Schulman G, Schwab SJ, Teehan BP, Toto R: Effect of dialysis dose and membrane flux in maintenance hemodialysis. N Engl J Med 2002;347:2010-2019.

$\checkmark 15$ Chertow GM, Levin NW, Beck GJ, Depner TA, Eggers PW, Gassman JJ, Gorodetskaya I, Greene T, James S, Larive B, Lindsay RM, Mehta RL, Miller B, Ornt DB, Rajagopalan S, Rastogi A, Rocco MV, Schiller B, Sergeyeva O, Schulman G, Ting GO, Unruh ML, Star RA, Kliger AS: In-center hemodialysis six times per week versus three times per week. N Engl J Med 2010;363:2287-2300.

16 Rocco MV, Lockridge RS Jr., Beck GJ, et al: The effects of frequent nocturnal home hemodialysis: the Frequent Hemodialysis Network Nocturnal Trial. Kidney Int 2011;80:1080-1091.

-17 Rocco MV, Daugirdas JT, Greene T, Lockridge $\mathrm{RS}$, Chan $\mathrm{C}$, Pierratos $\mathrm{A}$, Lindsay $\mathrm{R}$, Larive B, Chertow GM, Beck GJ, Eggers PW,
Kliger AS: Long-term effects of frequent nocturnal hemodialysis on mortality: the Frequent Hemodialysis Network (FHN) Nocturnal Trial. Am J Kidney Dis 2015;66:459-468.

18 Daugirdas JT, Greene T, Rocco MV, Kaysen GA, Depner TA, Levin NW, Chertow GM, Ornt DB, Raimann JG, Larive B, Kliger AS: Effect of frequent hemodialysis on residual kidney function. Kidney Int 2013;83:949-958.

9 Cooper BA, Branley P, Bulfone L, Collins JF, Craig JC, Dempster J, Fraenkel MB, Harris A, Harris DC, Johnson DW, Kesselhut J, Luxton G, Pilmore A, Pollock CA, Tiller DJ: The Initiating Dialysis Early and Late (IDEAL) study: study rationale and design. Perit Dial Int 2004;24:176-181.

20 Daugirdas JT, Depner TA, Greene T, Levin NW, Chertow GM, Rocco MV: Standard Kt/ Vurea: a method of calculation that includes effects of fluid removal and residual kidney clearance. Kidney Int 2010;77:637-644.

21 Diao Z, Zhang D, Dai W, Ding J, Zhang A, Liu $\mathrm{W}$ : Preservation of residual renal function with limited water removal in hemodialysis patients. Ren Fail 2011;33:875-877.

22 Lin YF, Huang JW, Wu MS, Chu TS, Lin SL, Chen YM, Tsai TJ, Wu KD: Comparison of residual renal function in patients undergoing twice-weekly versus three-times-weekly haemodialysis. Nephrology (Carlton) 2009; 14:59-64.

23 Fernández-Lucas M, Teruel-Briones JL, Gomis-Couto A, Villacorta-Pérez J, QueredaRodríguez-Navarro C: Maintaining residual renal function in patients on haemodialysis: 5 -year experience using a progressively increasing dialysis regimen. Nefrologia 2012;32: 767-776.

24 Zhang M, Wang M, Li H, Yu P, Yuan L, Hao C, Chen J, Kalantar-Zadeh K: Association of initial twice-weekly hemodialysis treatment with preservation of residual kidney function in ESRD patients. Am J Nephrol 2014;40:140150.

25 Termorshuizen F, Dekker FW, van Manen JG, Korevaar JC, Boeschoten EW, Krediet RT: Relative contribution of residual renal function and different measures of adequacy to survival in hemodialysis patients: an analysis of the Netherlands Cooperative Study on the Adequacy of Dialysis (NECOSAD)-2. J Am Soc Nephrol 2004;15:1061-1070.

26 Bargman JM, Thorpe KE, Churchill DN: Relative contribution of residual renal function and peritoneal clearance to adequacy of dialysis: a reanalysis of the CANUSA study. J Am Soc Nephrol 2001;12:2158-2162.

27 Hanson JA, Hulbert-Shearon TE, Ojo AO, Port FK, Wolfe RA, Agodoa LY, Daugirdas JT: Prescription of twice-weekly hemodialysis in the USA. Am J Nephrol 1999;19:625-633.

28 Lin X, Yan Y, Ni Z, Gu L, Zhu M, Dai H, Zhang W, Qian J: Clinical outcome of twiceweekly hemodialysis patients in Shanghai. Blood Purif 2012;33:66-72.

29 Suri RS, Larive B, Sherer S, Eggers P, Gassman J, James SH, Lindsay RM, Lockridge RS, Ornt
DB, Rocco MV, Ting GO, Kliger AS: Risk of vascular access complications with frequent hemodialysis. J Am Soc Nephrol 2013;24: 498-505.

30 Foley RN, Gilbertson DT, Murray T, Collins AJ: Long interdialytic interval and mortality among patients receiving hemodialysis. $\mathrm{N}$ Engl J Med 2011;365:1099-1107.

-31 Zhang H, Schaubel DE, Kalbfleisch JD, BraggGresham JL, Robinson BM, Pisoni RL, Canaud B, Jadoul M, Akiba T, Saito A, Port FK, Saran R: Dialysis outcomes and analysis of practice patterns suggests the dialysis schedule affects day-of-week mortality. Kidney Int 2012;81:1108-1115.

-32 Krishnasamy R, Badve SV, Hawley CM, McDonald SP, Boudville N, Brown FG, Polkinghorne KR, Bannister KM, Wiggins KJ, Clayton $\mathrm{P}$, Johnson DW: Daily variation in death in patients treated by long-term dialysis: comparison of in-center hemodialysis to peritoneal and home hemodialysis. Am J Kidney Dis 2013;61:96-103.

33 Foley RN, Herzog CA, Collins AJ; United States Renal Data System: Blood pressure and long-term mortality in United States hemodialysis patients: USRDS Waves 3 and 4 Study. Kidney Int 2002;62:1784-1790.

34 Burton JO, Jefferies HJ, Selby NM, McIntyre CW: Hemodialysis-induced cardiac injury: determinants and associated outcomes. Clin J Am Soc Nephrol 2009;4:914-920.

-35 Shoji T, Tsubakihara Y, Fujii M, Imai E: Hemodialysis-associated hypotension as an independent risk factor for two-year mortality in hemodialysis patients. Kidney Int 2004;66: 1212-1220.

36 Flythe JE, Kimmel SE, Brunelli SM: Rapid fluid removal during dialysis is associated with cardiovascular morbidity and mortality. Kidney Int 2011;79:250-257.

37 Susantitaphong P, Koulouridis I, Balk EM, Madias NE, Jaber BL: Effect of frequent or extended hemodialysis on cardiovascular parameters: a meta-analysis. Am J Kidney Dis 2012;59:689-699.

38 Caria S, Cupisti A, Sau G, Bolaso P: The incremental treatment of ESRD: a low-protein diet combined with weekly hemodialysis may be beneficial for selected patients. BMC Nephrol 2014;15:172.

-39 Stankuviene A, Ziginskiene E, Kuzminskis V, Bumblyte IA: Impact of hemodialysis dose and frequency on survival of patients on chronic hemodialysis in Lithuania during 1998-2005. Medicina (Kaunas) 2010;46:516521.

40 Elamin S, Abu-Aisha H: Reaching target hemoglobin level and having a functioning arteriovenous fistula significantly improve one year survival in twice weekly hemodialysis. Arab J Nephrol Transplant 2012;5:81-86.

41 Supasyndh O, Satirapoj B, Seenamngoen S, Yongsiri S, Choovichian P, Vanichakarn S: Nutritional status of twice and thrice-weekly hemodialysis patients with weekly $\mathrm{Kt} / \mathrm{V}>3.6$. J Med Assoc Thai 2009;92:624-631. 